УДК 398

\author{
НОВЫЙ ВЗГЛЯД \\ НА ЭТНИЧЕСКУЮ ИДЕНТИЧНОСТЬ СКИФОВ И САКОВ
}

(C) Марсель Бакиров

\title{
SCYTHIANS AND SAKA: DIVERSITY OF THE GENERAL CULTURE AND ETHNIC HETEROGENEITY
}

\begin{abstract}
Marsel Bakirov
This article is an excerpt from the main research on the ethnogenesis and ethnic history of the protoTürks. The author of the article argues that Iranian-centrists one-sidedly interpret the glottogonic processes in Eurasia, including the issue of the Sako-Scythians' origin and their ethnocultural characteristics. This article presents the ethno-defining features that were not taken into account earlier or were consciously ignored by Iranian scholars. The evidence base of the study is the Pra-Türkic vocabulary, restored by the author in the course of analyzing the cults of the snake and the wolf. The paper advocates the idea that the origin of the Turks is associated with a certain part of the Scythians-Sakas.
\end{abstract}

Keywords: Scytho-Saka, Turanians, ethnogenesis and ethnoculture, ethno-defining features, monoculture and polyculture, continuity, snake fighters and snake worshippers.

Настоящая статья представляет отрывок из основного исследования по этногенезу и этнической истории прототюрков. Автор статьи вступает в дискуссию с учеными-ираноцентристами, однобоко трактующими глоттогонические процессы Евразии, в том числе и вопрос о происхождении сако-скифов и их этнокультурных особенностях. В работе приводятся не учтенные ранее или сознательно проигнорированные иранистами этноопределяющие признаки. Доказательной базой исследования выступает пратюркская лексика, восстановленная автором статьи в ходе анализа культов змеи и волка. В работе отстаивается мысль о том, что происхождение тюрков связано с определенной частью скифов-саков.

Ключевые слова: скифо-саки, туранцы, этногенез и этнокультура, этноопределяющие признаки, монокультура и поликультура, преемственность, змееборцы и змеепочитатели.

Этническая и этнокультурная история скифов и саков до сих пор остается довольно противоречивой и далекой от окончательного решения, несмотря на то что в этой области трудами исследователей разных профилей и поколений было сделано очень много. Нежелание прислушиваться к мнениям друг друга, стремление во что бы то ни стало отстоять свою точку зрения, даже вопреки здравым идеям и обоснованным исследованиям, превратили эту историю в клубок загадок, распутывание которого требует значительных усилий.

В качестве типичного примера можно привести концепцию Б. Н. Грекова и А. Н. Мелюковой, которые в своем исследовании утверждают: «Единство языка всех скифских племен может быть усмотрено еще из преданий о происхождении скифов, которые переданы Геродотом. Лингвистическое изучение В. Ф. Миллера и после его работ принадлежность скифов и позднее сарматов к иранской ветви языков вполне принято лингвистами» [Граков, Мелюкова, с. 40].

Но такое утверждение явно не согласуется с реальными фактами. В. Ф. Миллер, на которого ссылаются эти авторы, никогда и нигде не сделал однозначного заключения, что скифы в этноязыковом отношении состояли якобы из одних только иранцев. Наоборот, из всего количества 425 «варварских» имен, зафиксированных в античных письменных источниках, он 258 считал неиранскими [Миллер, с. 101]. Да и свидетельство Геродота о том, что скифы нуждались в семи переводчиках, чтобы проехать к народу агрипеев, убедительно указывает на существование в Скифии различных по языку народностей.

Разумеется, среди ученых есть и другие исследователи, более объективные и здравомыслящие, которые допускают присутствие среди так называемых скифов и неиранских этносов. В их числе крупный антрополог В. П. Алексеев, пришедший к следующему заключению: «Вопреки 
мнению тех исследователей, которые видят генетические истоки скифо-сакских культур в единой этнической среде, палеоантропологические данные дают возможность поддержать другую гипотезу: скифо-сакская, или скифо-сибирская, культурная общность не образует генетического единства и сложилась на базе нескольких разных по происхождению антропологически своеобразных компонентов, которые и этнически могли существенно отличаться друг от друга» [Алексеев, с. 233-234].

Однако полемизирующих друг с другом ученых, особенно не консервативного склада, интересует не только физическая разнородность скифов, но и системные различия, скрывающиеся за кажущейся монокультурой. Эту схему решительно ломает известный казахский археолог и историк К. А. Акишев, который исходя из своих исследований утверждает: «Теория о единстве культур скифского времени евразийских степей основывалась исключительно на блеске золота и бронзы, на таких элементах культуры, как „скифская триада“"1, при этом недостаточно учитывались менее яркие, но не менее важные ее элементы, как погребальный обряд, керамические сосуды, предметы быта. Между тем эти составные части культуры имеют принципиальное значение для определения ее генезиса и выяснения этнической истории племен» [Акишев, с. 44].

Итоги исследований К. А. Акишева, а также археологические и палеоантропологические реалии из районов европейской Скифии и саков Азии, убеждают в том, что утвердившееся мнение о монокультурности этих регионов во многих аспектах неверно. Эти данные подтверждают, что культура этнически разных племен степной полосы Евразии была скифоидной лишь по формально-типологическим признакам и местной по этносоциальному содержанию, в том числе и всегда подчеркиваемая общность вооружения и конского снаряжения, в значительной степени также кажущаяся.

Скифская культура, конечно, не ограничивалась лишь материальной сферой, но охватывала также и духовную сферу, в том числе идеологические представления древних племен. Исходя из того, что индоиранская языковая семья входит в состав индоевропейской языковой общности, приверженцы теории ираноязычности скифов упорно пытаются разыскать параллели в эпических сюжетах и мотивах, пантеоне богов и мифологических верованиях и в искусстве «звериного стиля» с идеологическими представлениями ин-

\footnotetext{
${ }^{1}$ Триада - три характерных вида культуры: вооружение, конская упряжка и звериный стиль в искусстве.
}

доиранцев («Авеста») и индоариев («Ригведа»). Особую настойчивость и находчивость проявляет во всем этом археолог и историк Е. Е. Кузьмина, которая на протяжении многих лет придерживается теории тотальной, всеобщей ираноязычности скифов [Кузьмина].

Однако французский ученый Ж. Дюмезиль, изучавший скифское общество в аспекте преемственности и сравнительном плане с индоариями и древними иранцами («народ Авесты»), пришел к поразительному выводу о том, что скифское общество далеко уклонилось от индоевропейской, в том числе иранской модели. Вместе с тем Ж. Дюмезиль и его последователи установили, что модель скифского общества гораздо больше соответствует социальной структуре сарматов, хунну и даже средневековых казахов и монголов XV-XVIII веков, чем индоевропейскому индоиранскому обществу III-II тысячелетий до н. э. [Дюмезиль, с. 155, 157]. А Е. В. Черненко не только ставит под сомнение «иранское единство» скифов, но и полагает вполне правомерной реконструкцию многих сторон скифского общества на базе аналогии с евразийскими кочевниками [Вопросы истории, 1978, № 8, с. 69].

Сторонники теории иранского всеобщего единства скифов безапелляционно заявляют, что алтайские и тюркоязычные племена продолжали у себя многие социальные институты и соответствующие им ритуалы и символы не в порядке этнической преемственности или наследования, а заимствовали их якобы от общей модели у ираноязычных скифов, будучи культурно отсталыми и более поздними пришельцами. Как тут не вспомнить пресловутую «теорию влияний», сопровождающую индоевропейскую науку, которая чаще всего решает культурные и языковые параллели в духе влияния «большого» народа на «малый».

Одной из базовых идеологических мотивировок этнического единства скифских племен считается генеалогическая легенда о происхождении их «царей» / ксай, то есть в данном случае трех сыновей от одного отца - Таргитая, которая якобы подтверждает генетическое родство всех скифов. Однако давно замечено, что подобные легенды (вспомним, например, библейские легенды о сыновьях Ноя и Яфета) чаще всего не отражают кровного родства между условно объединенными и легендарными родоначальниками различных племен и народов. Да и отождествление окончания -ксай имен упомянутых сыновей - Арпоксая, Колоксая и Липоксая - с явной натяжкой с древнеиранским словом «хй́ауа», означающим «царь, владыка», не может считаться безупречным. Насколько нам известно, присут- 
ствующее в легенде имя Таргитай в раннем средневековье всплыло у тюркоязычных аваров: руководителя делегации, посланной от них в Византию, называли именно так. Кроме того, нам кажется более убедительным то, что такие окончания имен, как -тай, -сай (а не ксай!) отнюдь не являются чуждыми и для древних тюркоязычных имен: Артай, Алатай, Матай, Отей / Атей, Арсай, Уксай, Урсай, Турксай, Хорасай, Токсай [Магницкий]. Отметим, что у приволжских булгар и чувашей были идентичные имена и без окончания -сай-: Колак, Арбак / Арпак. Компонент же -сай в тюркских языках означает «знатный», «благородный»: сай-ыг (шорск.), сай-ын (осм.), сай-дут (алт.).

Французский ориенталист Дюмизель, хотя и предполагал (вернее, допускал), что свойственная древним индоариям и иранцам модель, вероятно, продолжала существовать у скифов в сфере их идеологии, на деле же в скифской духовной культуре, включая мифологию и религиозные представления, отсутствует ряд наиболее характерных для «Ригведы» и «Авесты» идеологических особенностей и этноопределяющих признаков.

Приведем примечательный и в высшей степени поразительный пример, который никак не хотят замечать или, скорее всего, сознательно обходят сторонники всеобщего иранизма скифов и саков. Как установлено исследователями, учеными многих поколений, индоевропейские народы, включая индоариев и иранцев, были змееборцами - яростными противниками культа змей [Гамкрелидзе, Иванов, с. 527], [Мифы народов мира, с. 530]. И неслучайно даже несколько веков спустя на основе этих верований в христианской религии прочно утвердилось отождествление змеи с дьяволом, сатаной, принявшим обличие змея. Кстати, в силу принадлежности славянских племен к индоевропейскому единству, в их мифологии и фольклоре тоже довольно широко представлены змееборческая идея и сюжет. Притом образ змеи-дракона в славянском эпосе обычно ассоциируется с кочевыми племенами, в том числе и древними тюркскими кочевниками. В мифологических текстах названных народов находящийся наверху бог Громовержец преследует змея или змееобразного существа, находящегося внизу и выступающего в качестве представителя нижнего, враждебного мира, и в конце концов убивает его, освободив тем самым удерживаемые змеем скот и водный источник. Вспомним, например, из «Ригведы» главу пантеона богов индоариев - бога грозы и войны Индру, убивающего змея Вритры, перегородившего течение рек, из «Авесты»- верховное божество иранцев по имени Ахура-Мазда, противостоящее главе сил зла и тьмы по имени Ангро-Манью, который породил вредоносную, по их представлению, змею и создал страну «рыжеватых змей» (на наш взгляд, здесь имеется в виду Туран с его жителями, который находился во враждебных отношениях с Ираном).

Туранский правитель был ярым противником зороастризма, который исповедовали иранские оседлые племена, и вел непримиримую борьбу с покровителем пророка Заратуштры КавиВиштаспом [Гуриев, с. 24]. В авестийской или иранской мифологии к этому же семантикоидеологическому ряду относится трехглавый дракон Ажи-Дахака. Вторая часть этого имени, по всей вероятности, взаимосвязана с названием туранского племени дахов, которые, по выражению персидского царя Дария (522-486 до н. э.), «не чтили Ахуру Мазду». В легендарной истории Ажи-Дахака - царь-узурпатор, захвативший власть над частью территории Ирана. В «Авесте» - трехглавый дракон, его противником является змееборец Траэтаон (в персидском Фретон / Фаридон).

Зороастрийской религии иранцев («Авеста») свойственен дух нетерпимости, неприязни к «кочевым варварам»: «Только правоверного маздаяниста, зороастрийца это учение считает подлинным человеком: к чужим народам зороастризм внушает ненависть, они для него - неарийцы, ,люди-насекомые“, , „змееобразные существа“» (Ясна, XXXIV, 5). Их истребление угодно Ахуро-Мазде. Эта тенденция намечена в «Гатах», в «Младшей Авесте» же эта человеконенавистническая сторона учения «расцветает пышным цветом» [Кузнецов, с. 241]. Пророк Заратуштра (др.греч. Зороастр) идеализировал «праведную» хозяйственную жизнь оседлых земледельцевиранцев, которую он резко противопоставлял неправедному кочевническому образу туранцев.

Если допустить, что скифские племена по этносу и языку являлись иранцами, то в этом случае они должны были сохранить хотя бы в пережиточной форме следы змееборческой идеологии, весьма характерной для их предков. Но все без исключения источники, непосредственно повествующие о скифах, об этом молчат. В скифской мифологии и эпосе нет ни божества, ни героя, носящего змееборческий характер.

Зато у этого полиэтнического народа не только в мифологии, но и в изобразительном искусстве наличествует культ змеи. В частности, в греческих источниках сохранилась своеобразная генеалогическая легенда о происхождении скифов от полудевы-полузмеи, в нижней части туловища которой - ноги в виде змеи. Исследова- 
тели этот образ называют то просто мифической змееногой праматерью, то богинейпрародительницей, а некоторые даже отождествляют ее со скифской богиней земли и воды, которая называлась Апи. Эллинизированная легенда, сохраненная Геродотом, гласит, что Геракл был вынужден вступить со змеевидной девой в любовную связь, чтобы вернуть назад упряжных коней, пропавших во время его сна. Женщиназмея родила от него три сына. Скиф сумел натянуть оставленный Гераклом лук, то есть справился с задачей, которую перед детьми поставила мать. Братья были изгнаны, а он остался жить в стране, и от него произошли скифские цари.

Не задумываясь о сути содержания этой легенды, одни исследователи (Е. Е. Кузнецова) упорно пытаются разыскать зооморфные параллели, то есть звериные образы и символы из мифологии индоариев и иранцев, оставаясь, разумеется, на позиции «единого иранизма» скифов. Другие авторы им возражают: «Никаких свидетельств о зооморфных воплощениях скифских богов источники не содержат» (Д. С. Раевский). Некоторые же исследователи, в их числе и почтенный археолог и историк Б. А. Рыбаков, даже умудряются сопоставить и сблизить скифского родоначальника Таргитая с иранским змееборцем Траэтотоаном (Феридуном), индийским Траитоном, а также греческим Гераклом, которые, согласно мифам, выступают как победители трехглавых змей-драконов. Это явно противоречит содержанию скифской генеалогической легенды, так как в ней змееногая дева не погибает от рук змееборца, как требует этого змееборческая идеология иранцев, а предстает целойневредимой, главное - как почитаемая скифами тотем-родоначальник.

Вот тут-то мы кардинально расходимся во взглядах с приверженцами «единого или тотального иранизма» скифских племен и твердо и решительно склоняемся к тюркоязычности части из них. Ибо, как установлено наукой, именно для древнетюркских племен, в противовес индоевропейцам и иранцам, с незапамятных времен в различных формах было характерно почитание змей. Мы имеем в виду в данном случае не только «белую змею», представленную в мифологии и фольклоре тюркских народов, но и одноголовую крылатую змею-сазагана, этимология которого, как мы считаем, восходит к сакскому слову «сазда» (sazda) со значением «змея». А пришедший из индоевропейской и иранской мифологии многоголовый змей-чудовище, который нашел отражение в волшебных сказках, был враждебным существом и для наших предков.
Культ змеи-дракона от скифов и саков далее был унаследован хуннскими и древнетюркскими племенами. В нашей монографии «Древнетюркская поэзия» [Бакиров] приводятся многообразные примеры, подтверждающие этот неоспоримый факт. Некоторые племена, например кипчакская династия шаракунов, кимаки и отдельные уйгурские роды и ханы, точно так же, как и скифы, свое родословие связывали со змеейсазаганом. Этот же образ, выступающий в роли мифологического оберега и защитника, занял почетное место в государственных эмблемах или своего рода гербах Булгарского царства и Казанского ханства, а в государственном, «цесарском» флаге этого ханства желтого цвета, напечатанном в 1705 году в сочинении Карлуса Алярда в Амстердаме, также красуется изображение крылатой змеи-сазагана [Мифологическое драконоведение, с. 282].

Все вышеизложенное, по нашему твердому убеждению, дает веское и прочное основание утверждать, что мифологический и обожествленный образ змеи-дракона с древнейших времен выступал и проявлял себя как этнический символ, или, другими словами, служил этноопределяющим показателем, позволяющим отличить тюркский кочевой мир от иранцев и шире - от индоевропейцев.

Другой зооморфный сакрализованный образ у скифов, позволяющий размышлять об этнической идеологии и принадлежности части скифов к тюркскому миру, - это волк. Если у подавляющего большинства индоевропейцев волк считался вредоносным, враждебным зверем, а мифологический «фольклорный мотив борьбы с волком (у них же) интерпретировался как семантический эквивалент мотиву змееборчества» (А. А. Потебня, Е. Л. Мороз), то у хуннов и тюркоязычных народов, судя по историческим данным, это животное почиталось и даже у некоторых племен воспринималось как тотем-прародитель. Эта традиция, безусловно, также восходит к скифосакской среде, которая нашла отражение в искусстве «звериного стиля». Об этом, в частности, свидетельствуют изображения волка на бляхах и рукоятках мечей в позе свернувшейся змеи, то есть в позе зооморфного образа и животного, сакрализованного и почитаемого отдельными племенами причерноморских скифов и среднеазиатских саков. И толкование А. А. Потебни о взаимозаменяемости и формальной тождественности волка и змеи, причисляя, таким образом, и волка в разряд вредоносных животных [Раевский, с. 119], отражает мировоззрение индоариев и в данном случае работает в пользу религиозных воззрений скифов (и, разумеется, древних тюр- 
ков), почитавших и обожествлявших оба названных животных.

В конце приведем несколько выявленных и этимологизированных нами на тюркской основе любопытных и довольно значимых сакскотюркских лексических схождений, относящихся к среднеазиатскому региону. Это, во-первых, текст-легенда на серебряной монете с видоизмененным греческим алфавитом - «TUPAN NOVNTOC HPAOI $\Sigma$ ANAB», означающая «Туранская неизменность $\sim$ Герай шаньйы». Второе древнее слово-корень этого текста «нау» со значениями «равнина», «низменность» в искомом, первозданном виде сохранилось, оказывается, у сибирских (тобольских) татар [Радлов, с. 693]. Да и порядок слов на монете точь-в-точь соответствует тюркскому построению речи (правда, к тюркскому окончанию родительного падежа по местной нумизматической традиции присоединен греческий аффикс принадлежности ос). Кроме названия «Туранская низменность», по данным авторов различного периода, эта же местность носила и другие схожие названия: у Геродота «Равнина саков», у Стработа - «Равнина массагетов». В настоящее время снова задействовано древнее, первоначальное слово «Туран»: «Туранская низменность».

Вот еще нововыявленные антропонимы: название озера Кансуа / Кансоуа, означающее потюркски «Овечий водоем (река)», название озера Чайчаста, первая часть которого «чай» (параллельные фонетические варианты «сай», «зай») также соответствует тюркским значениям «водоем», «река». Собственное же имя сакского царя в Передней Азии Тугдаммы, в некоторых греческих источниках Дuүðamic, не имеющего, по признанию самих иранистов, удовлетворительного объяснения на иранских языках, мы уверенно связываем с общетюркским собственным именем Туктамыш (в древнетюркском toqtamiš) от праформы тукта - 'остановиться', 'остановись'. Это табуированное имя, как известно, давалось в целях приостановки возможного летального исхода младенца в семье или предупреждения и избежания преждевременной смерти носителя данного имени. В этот же перечень, конечно, можно было бы включить объемный лексический корпус начиная с зафиксированных впервые в «Ригведе» и «Авесте» истинно тюркских слов paš / баш 'голова', kšo / киши 'человек', заканчивая древнейшими глаголами с̌а / с̌aq 'высекать' (искру, огонь), уóga / jeg 'запрягать', qor / kur 'сооружать', от него же слово «курган».

Исходя из восстановленной пратюркской лексики, а также этноопределяющей культурно- идеологической преемственности мы решительно и твердо связываем происхождение тюрков с определенной частью скифов-саков, которые, в свою очередь, своими глубинными корнями уходят в генетико-контактный ареальный языковой союз Ближнего Востока.

\section{Список литературы}

Акишев K. А. Саки азиатские и скифы европейские (Общее и особенное в культуре) // Археологические исследования в Казахстане. Алма-Ата, 1973. С. 43-58.

Алексеев В. П. Историческая антропология и этногенез. М.: Наука, 1989. 446 с.

Бакиров М. Х. Древнетюркская поэзия. Казань: Тат. книжное изд-во, 2014. 390 с.

Гамкрелидзе Т. В., Иванов В. В. Индоевропейский язык и индоевропейцы. В 2-х кн. Кн. 2. Тбилиси: издво Тбилисского университета, 1984. 1328 с.

Граков Б. Н., Мелюкова А. И. Об этнических и культурных различиях в степных и лесостепных областях Европейской части России в скифское время // Вопросы скифо-сарматской археологии. М., 1952. С. 39-93.

Гуриев Т. А. Из жемчужины Востока: «Авеста». Владикавказ, 1933. 38 с.

Дюмезиль Ж. Скифы и нарты. М.: Наука, 1990. $232 \mathrm{c}$.

Кузнецов Б. И. Древний Иран и Тибет. СПб.: Евразия, $1998.351 \mathrm{c}$.

Кузьмина Е. Е. О «прочтении» изобразительных памятников искусства Евразийских степей скифского времени // Вестник древней истории. 1983. № 1. С. 95-105.

Магницкий B. К. Чувашские (читай: древнебулгарские - М. Б.) имена. Казань, 1915.

Миллер В. Ф. Осетинские этюды. В 3-х частях. Часть третья. М., 1887. 216 с.

Мифологическое драконоведение. М.: Вече, 2007. $512 \mathrm{c}$.

Мифы народов мира. Энциклопедия: в 2 т. Т. 2. М.: Советская энциклопедия, 1988. 719 с.

Радлов В. В. Опыт словаря тюркских наречий. Т. 3. СПб., 1995. С. 693.

Раевский Д. Р. Модель мира скифской культуры М.: Наука, 1985. 256 с.

\section{References}

Akishev, K. A. (1973). Saki aziatskie $i$ skify evropeiskie (Obshchee i osobennoe v kul'ture) [The Asian Sakas and the European Scythians (General and Special in Culture)]. Arkheologicheskie issledovaniia v Kazakhstane. Alma-Ata, pp. 43-58. (In Russian)

Alekseev, V. P. (1989). Istoricheskaia antropologiia $i$ etnogenez [Historical Anthropology and Ethnogenesis]. 446 p. Moscow, Nauka. (In Russian)

Bakirov, M. Kh. (2014). Drevnetiurkskaia poeziia [Old Turkic Poetry]. 390 p. Kazan', Tat. knizhnoe izd-vo. (In Russian) 
Diumezil', Zh. (1990). Skify $i$ narty [The Scythians and the Narts]. 232 p. Moscow, Nauka. (In Russian)

Gamkrelidze, T. V., Ivanov, V. V. (1984). Indoevropeiskii iazyk $i$ indoevropeitsy [The IndoEuropean Language and the Indo-Europeans]. V 2-kh kn. Kn. 2.1328 p. Tbilisi, izd-vo Tbilisskogo universiteta. (In Russian)

Grakov, B. N., Meliukova, A. I. (1952). $O b$ etnicheskikh $i$ kul'turnykh razlichiiakh $v$ stepnykh $i$ lesostepnykh oblastiakh Evropeiskoi chasti Rossii v skifskoe vremia [On Ethnic and Cultural Differences in the Steppe and Forest-Steppe Regions of the European part of Russia in the Scythian Times]. Voprosy skifosarmatskoi arkheologii. Moscow, pp. 39-93. (In Russian)

Guriev, T. A. (1933). Iz zhemchuzhiny Vostoka: "Avesta" [From the Oriental Gems: "Avesta"]. 38 p. Vladikavkaz. (In Russian)

Kuz'mina, E. E. (1983). O "prochtenii" izobrazitel'nykh pamiatnikov iskusstva Evraziiskikh stepei skifskogo vremeni [On the "Reading" of the Fine Art Monuments of the Eurasian Steppes in the Scythian Period]. Vestnik drevnei istorii. No. 1, pp. 95-105. (In Russian)

\section{Бакиров Марсель Хаернасович,} доктор филологических наук, профессор, Республиканский центр развития традиционной культуры, 420015, Россия, Казань, Пушкина, 66/33. bekmetov@list.ru
Kuznetsov, B. I. (1998). Drevnii Iran i Tibet [Ancient Iran and Tibet]. 351 p. St. Petersburg, Evraziia. (In Russian)

Magnitskii, V. K. (1915). Chuvashskie (chitai: drevnebulgarskie - M. B.) imena [Chuvash (read: Old Bulgarian - M. B.) Names]. Kazan'. (In Russian)

Mifologicheskoe drakonovedenie (2007) [Mythological Dragon Studies]. 512 p. Moscow, Veche. (In Russian)

Mify narodov mira. Entsiklopediia: v 2 t. (1988) [Myths of the Peoples of the World. Encyclopedia: In Two Volumes]. T. 2, 719 p. Moscow, Sovetskaia entsiklopediia. (In Russian)

Miller, V. F. (1887). Osetinskie etiudy [Ossetian Etudes]. V 3-kh chastiakh. Chast' tret'ia. 216 p. Moscow. (In Russian)

Radlov, V. V. (1995). Opyt slovaria tiurkskikh narechii [The Experience of the Turkic Adverbs Dictionary]. T. 3, p. 693. St. Petersburg. (In Russian)

Raevskii, D. R. (1985). Model' mira skifskoi kul'tury [The Model of the Scythian Culture World]. 256 p. Moscow, Nauka. (In Russian)

The article was submitted on 13.03.2019

Поступила в редакцию 13.03.2019

\author{
Bakirov Marsel Haernasovich, \\ Doctor of Philology, \\ Professor, \\ Republican Centre for the Development \\ of Traditional Culture, \\ 66/33 Pushkin Str., \\ Kazan, 420015, Russian Federation. \\ bekmetov@list.ru
}

